OPEN ACCESS

Edited by:

Baiquan Liu,

Sun Yat-sen University, China

Reviewed by:

Fei Chen,

Hangzhou Dianzi University, China

Xueyun Liu,

Ningbo University, China

*Correspondence:

Peng Xiao

xiaopeng@fosu.edu.cn

Specialty section:

This article was submitted to

Nanoscience,

a section of the journal

Frontiers in Chemistry

Received: 11 November 2020 Accepted: 10 December 2020

Published: 08 January 2021

Citation:

Yuan J, Wang W, Ye Y, Deng T, Ou D,

Cheng J, Yuan S and Xiao P (2021)

Effect of $\mathrm{BaF}_{2}$ Variation on Spectroscopic Properties of $\mathrm{Tm}^{3+}$ Doped Gallium Tellurite Glasses for

Efficient $2.0 \mu \mathrm{m}$ Laser.

Front. Chem. 8:628273.

doi: 10.3389/fchem.2020.628273

\section{Effect of $\mathrm{BaF}_{2}$ Variation on Spectroscopic Properties of $\mathrm{Tm}^{3+}$ Doped Gallium Tellurite Glasses for Efficient $2.0 \mu \mathrm{m}$ Laser}

\author{
Jian Yuan ${ }^{1,2}$, Weichao Wang ${ }^{2}$, Yichen $\mathrm{Ye}^{2}$, Tingting Deng ${ }^{1}$, Deqian $\mathrm{Ou}^{1}$, Junyang Cheng ${ }^{1}$, \\ Shengjin Yuan ${ }^{1}$ and Peng Xiao ${ }^{1 *}$ \\ ${ }^{1}$ Guangdong-Hong Kong-Macao Intelligent Micro-Nano Optoelectronic Technology Joint Laboratory, Foshan University, \\ Foshan, China, ${ }^{2}$ State Key Laboratory of Luminescent Materials and Devices, South China University of Technology, \\ Guangzhou, China
}

The effects of substitution of $\mathrm{BaF}_{2}$ for $\mathrm{BaO}$ on physical properties and 1. $8 \mu \mathrm{m}$ emission have been systematically investigated to improve spectroscopic properties in $\mathrm{Tm}^{3+}$ doped gallium tellurite glasses for efficient $2.0 \mu \mathrm{m}$ fiber laser. It is found that refractive index and density gradually decrease with increasing $\mathrm{BaF}_{2}$ content from 0 to 9 mol.\%, due to the generation of more non-bridging oxygens. Furthermore, $\mathrm{OH}^{-}$absorption coefficient $\left(\alpha_{\mathrm{OH}}\right)$ reduces monotonically from 3.4 to $2.2 \mathrm{~cm}^{-1}$ and thus emission intensity near $1.8 \mu \mathrm{m}$ in gallium tellurite glass with $9 \mathrm{~mol} . \% \mathrm{BaF}_{2}$ is 1.6 times as large as that without $\mathrm{BaF}_{2}$ while the lifetime becomes 1.7 times as long as the one without $\mathrm{BaF}_{2}$. Relative energy transfer mechanism is proposed. The maximum emission cross section and gain coefficient at around $1.8 \mu \mathrm{m}$ of gallium tellurite glass containing $9 \mathrm{~mol} . \% \mathrm{BaF}_{2}$ are $8.8 \times 10^{-21} \mathrm{~cm}^{2}$ and $3.3 \mathrm{~cm}^{-1}$, respectively. These results indicate that $\mathrm{Tm}^{3+}$ doped gallium tellurite glasses containing $\mathrm{BaF}_{2}$ appear to be an excellent host material for efficient $2.0 \mu \mathrm{m}$ fiber laser development.

Keywords: gallium tellurite glass, $\mathrm{Tm}^{3+}$ doped, $\mathrm{OH}^{-}, 1.8 \mu \mathrm{m}$ emission, $\mathrm{BaF}_{2}$

\section{INTRODUCTION}

Over the past few decades, fiber lasers operating in eye-safe $2.0 \mu \mathrm{m}$ spectral region have attracted a great deal of attention due to strong absorption band of several chemical compounds $\left(\mathrm{H}_{2} \mathrm{O}\right.$, $\mathrm{CO}_{2}, \mathrm{~N}_{2} \mathrm{O}$, etc.) in this region (Chen et al., 2010). Therefore, there are some potential applications in eye-safe laser radar, material processing, laser surgery, remote sensing and effective pump sources as mid-infrared lasers and optical parametric oscillators (Geng et al., 2011; Geng and Jiang, 2014; Slimen et al., 2019; Wang et al., 2019). Up to now, active ions for $2.0 \mu \mathrm{m}$ laser have been mainly focused on $\mathrm{Tm}^{3+}$ and $\mathrm{Ho}^{3+}$ ions arising from $\mathrm{Tm}^{3+}:{ }^{3} \mathrm{~F}_{4} \rightarrow{ }^{3} \mathrm{H}_{6}$ and $\mathrm{Ho}^{3+}:{ }^{5} \mathrm{I}_{7} \rightarrow{ }^{5} \mathrm{I}_{8}$ transition. Compared with $\mathrm{Ho}^{3+}, \mathrm{Tm}^{3+}$ owns very strong absorption band of ${ }^{3} \mathrm{H}_{6} \rightarrow{ }^{3} \mathrm{H}_{4}$ transition and thus can be effectively pumped by commercial high-power $808 \mathrm{~nm}$ laser diode. Under the pump scheme, a quantum efficiency of $200 \%$ can be expected from "two-for-one" cross relaxation process $\left({ }^{3} \mathrm{H}_{4}+{ }^{3} \mathrm{H}_{6} \rightarrow 2^{3} \mathrm{~F}_{4}\right)$ (Richards et al., 2010). In addition, broad emission bandwidth of $\mathrm{Tm}^{3+}:{ }^{3} \mathrm{~F}_{4} \rightarrow{ }^{3} \mathrm{H}_{6}$ transition about $300 \mathrm{~nm}$ is advantageous to the generation of femtosecond pulse (Agger et al., 2004). 
In pursuit of efficient $2.0 \mu \mathrm{m}$ laser, different glass hosts have been extensively investigated and the laser operation has been demonstrated in silicate, fluoride, germanate and tellurite glasses (Richards et al., 2010; He et al., 2013; Wang et al., 2019). Among these glass hosts, tellurite glasses own a lot of advantage such as broad infrared transmission region, lower phonon energy, high rare-earth ion solubility, high refractive index $(\sim 2)$ and easy fabrication with low melting temperature(Richards et al., 2010). Recently, our groups have exploited several new tellurite glass systems such as $\mathrm{TeO}_{2}-\mathrm{Ga}_{2} \mathrm{O}_{3}-\mathrm{BaO}$ (TGB) and $\mathrm{TeO}_{2}-\mathrm{Ga}_{2} \mathrm{O}_{3}-\mathrm{ZnO}$ (TGZ) with excellent glass-forming ability, thermal stability and $2.0 \mu \mathrm{m}$ spectroscopic properties (Li et al., 2019; Mao et al., 2020). To further improve $2.0 \mu \mathrm{m}$ emission properties, it is very essential to reduce the hydroxyl content in glasses because $\mathrm{OH}^{-}$groups are the main energy loss channels for active ions and can result in strong $2.0 \mu \mathrm{m}$ fluorescence quenching (Terra et al., 2006). We found that the strength of interaction between $\mathrm{Tm}^{3+}$ and $\mathrm{OH}^{-}\left(12.9 \times 10^{-19} \mathrm{~cm}^{4} / \mathrm{s}\right)$ was stronger than that between $\mathrm{Er}^{3+}$ and $\mathrm{OH}^{-}\left(1.9 \times 10^{-19} \mathrm{~cm}^{4} / \mathrm{s}\right)$ (Yuan et al., 2014).

Herein, based on the composition of TGB glass with good thermal stability, we systematically investigate the effects of substitution of $\mathrm{BaF}_{2}$ for $\mathrm{BaO}$ on physical properties and $1.8 \mu \mathrm{m}$ emission properties. Density, refractive index, Raman spectra, absorption spectra and emission spectra were measured along with the lifetime of $\mathrm{Tm}^{3+}:{ }^{3} \mathrm{~F}_{4}$ energy level. Moreover, energy transfer mechanism is proposed and emission cross section and gain coefficient of $\mathrm{Tm}^{3+}:{ }^{3} \mathrm{~F}_{4} \rightarrow{ }^{3} \mathrm{H}_{6}$ transition in TGB glass with $9 \mathrm{~mol} . \% \mathrm{BaF}_{2}$ are determined.

\section{MATERIALS AND METHODS}

$\mathrm{Tm}^{3+}$ doped gallium tellurite glasses (TGB) with the molar compositions of $80 \mathrm{TeO}_{2}-10 \mathrm{Ga}_{2} \mathrm{O}_{3}-(9-\mathrm{x}) \mathrm{BaO}-\mathrm{xBaF}_{2}-1 \mathrm{Tm}_{2} \mathrm{O}_{3}$ ( $\mathrm{x}$ $=0,3,6$, and 9) were prepared by the conventional meltquenching method. $\mathrm{TeO}_{2}, \mathrm{Ga}_{2} \mathrm{O}_{3}, \mathrm{BaO}, \mathrm{BaF}_{2}$ and $\mathrm{Tm}_{2} \mathrm{O}_{3}$ with 99.99\% purity (Aladdin) were used as raw chemicals. Appropriate amounts of these chemicals $(\sim 20 \mathrm{~g})$ were well mixed and then melted in an alumina crucible with an alumina lid at $\sim 950^{\circ} \mathrm{C}$ for $30 \mathrm{~min}$. Afterwards, the melts were poured onto a preheated graphite mold and further annealed at $330^{\circ} \mathrm{C}$ for $2 \mathrm{~h}$, after which they were cooled slowly inside the furnace to room temperature. The annealed samples for the optical property measurements need to be double-sided polishing into $10 \times 10 \times 1.5 \mathrm{~mm}^{3}$ cylinders. Densities of glasses were determined by the Archimedes' principle using the distilled water as the medium. The refractive index of all the samples was measured by the prism coupling method (Metricon Model $2010)$ at $633,1,309$, and $1,533 \mathrm{~nm}$ with an error of $\pm 5 \times$ $10^{-4}$. The infrared transmittance spectra were obtained using Vector 33 Fourier transform infrared (FTIR) spectrophotometer (Bruker, Switzerland). The Raman spectra were measured by Raman spectrometer (Renishawin Via, Gloucestershire, UK) and $532 \mathrm{~nm}$ laser as the excitation source. Optical absorption spectra measurements were performed on a Perkin-Elmer
TABLE 1 | The refractive index and density of TGB glasses with different $\mathrm{BaF}_{2}$ contents.

\begin{tabular}{lcccc}
\hline Sample & $\boldsymbol{n}(@ \mathbf{6 3 3} \mathbf{n m})$ & $\boldsymbol{n}(@ \mathbf{1 , 3 0 9} \mathbf{n m})$ & $\boldsymbol{n}(@ \mathbf{1 , 5 3 3} \mathbf{n m})$ & $\boldsymbol{\rho}\left(\mathbf{g} / \mathbf{c m}^{\mathbf{3}}\right)$ \\
\hline $\mathrm{x}=0$ & 1.9723 & 1.9324 & 1.9289 & 5.265 \\
$\mathrm{x}=3$ & 1.9490 & 1.9097 & 1.908 & 5.219 \\
$\mathrm{x}=6$ & 1.9281 & 1.8920 & 1.8904 & 5.140 \\
$\mathrm{x}=9$ & 1.9132 & 1.8792 & 1.8769 & 5.128
\end{tabular}

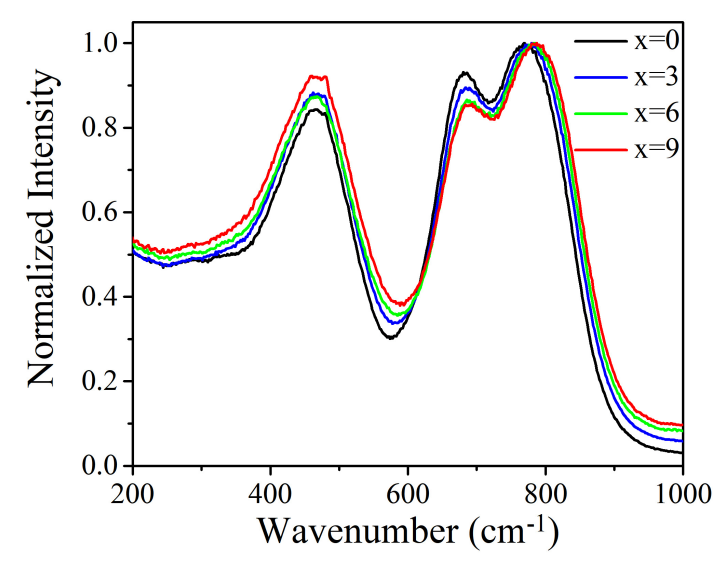

FIGURE 1 | Normalized Raman spectra of TGB glasses with different $\mathrm{BaF}_{2}$ amounts.

Lambda 900/UV/VIS/NIR spectrophotometer. The fluorescence spectra were recorded by a computer-controlled Triax 320 type spectrofluorimeter (Jobin-Yvon Corp.) equipped with an InAs detector upon the excitation of an $808 \mathrm{~nm}$ LD. After exciting the samples with an $808 \mathrm{~nm} \mathrm{LD}$, InAs detector was used to detect the lifetime of $\mathrm{Tm}^{3+}:{ }^{3} \mathrm{~F}_{4}$ energy level $(1.8 \mu \mathrm{m})$ along with a digital phosphor oscilloscope (TDS3012C, Tektronix, America) and signal generator. All of the measurements were carried out at room temperature.

\section{RESULTS AND DISCUSSION}

Table 1 presents the refractive index $(n)$ and density $(\rho)$ of TGB glasses with different $\mathrm{BaF}_{2}$ contents. It is found that the refractive index and density monotonously decrease when $\mathrm{BaF}_{2}$ content increases from 0 to $9 \mathrm{~mol} \%$ in step of $3 \mathrm{~mol} . \%$. This indicates that the addition of $\mathrm{BaF}_{2}$ makes glass network looser (Yang et al., 2017), which is demonstrated by the Raman spectra as shown Figure 1. It is noted that three major bands appear in TGB glasses with different $\mathrm{BaF}_{2}$ amounts. The peak $A$ at $\sim 466 \mathrm{~cm}^{-1}$ is assigned to the symmetrical stretching or bending vibrations of Te-O-Te linkages at corner sharing sites (Murugan and Ohishi, 2004; Jose et al., 2007). The peak $\mathrm{B}$ at $\sim 682 \mathrm{~cm}^{-1}$ is ascribed to the anti-symmetric stretching vibrations of Te-O-Te linkages constructed by two un-equivalent $\mathrm{Te}-\mathrm{O}$ bonds containing bridging oxygens (BO) in $\mathrm{TeO}_{4}$ trigonal bipyramid and the peak $\mathrm{C}$ is due to the symmetrical stretching vibrations of $\mathrm{Te}^{-} \mathrm{O}^{-}$and $\mathrm{Te}=\mathrm{O}$ 


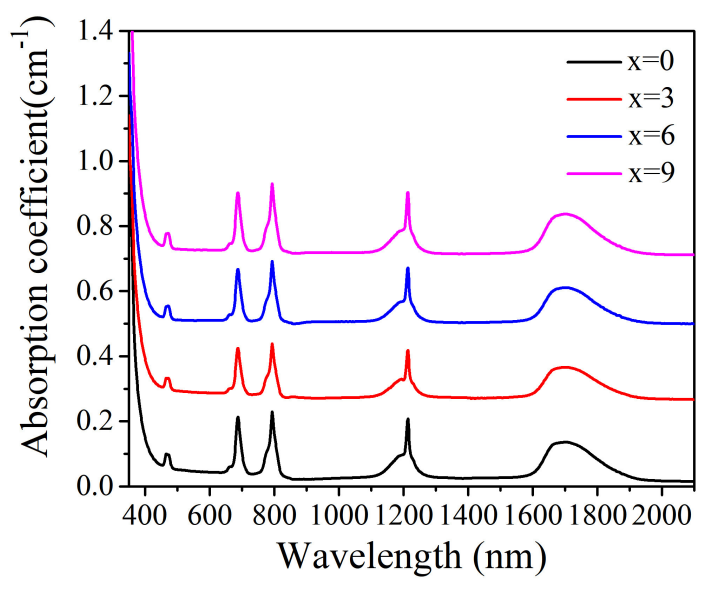

FIGURE 2 | Absorption spectra in TGB glasses with different $\mathrm{BaF}_{2}$ contents.

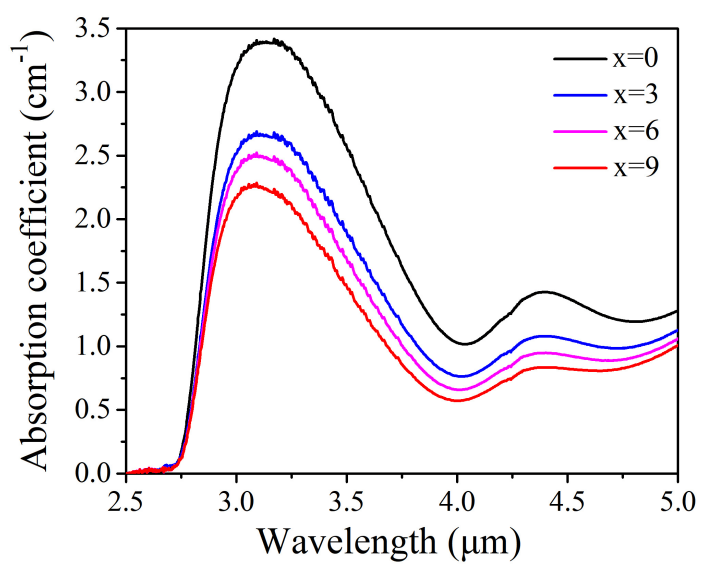

FIGURE 3 | FTIR spectra of TGB glasses with different proportions of $\mathrm{BaF}_{2}$.

bonds with non-bridging oxygens (NBO) in $\mathrm{TeO}_{3}$ trigonal pyramid and $\mathrm{TeO}_{3+1}$ polyhedra (Murugan and Ohishi, 2004; Jose et al., 2007). It is worth noting that the position of peak C slightly shifts from 769 to $787 \mathrm{~cm}^{-1}$ and normalized intensity of peak $\mathrm{B}$ declines with the increment of $\mathrm{BaF}_{2}$ from 0 to $9 \mathrm{~mol} . \%$, revealing that glass network structure is broken and more non-bridging oxygens arise. Such low phonon energy of TGB glasses is able to effectively decrease nonradiative relaxation in favor of the enhancement of $2.0 \mu \mathrm{m}$ emission intensity.

Figure 2 shows the typical absorption spectra of TGB glasses in the wavelength range from 350 to $2,100 \mathrm{~nm}$. The absorption spectrum consists of five absorption bands of $\mathrm{Tm}^{3+}$ centered at $473,687,794,1,214$, and $1,700 \mathrm{~nm}$, corresponding to respective transitions from the ${ }^{3} \mathrm{H}_{6}$ ground state to excited states ${ }^{1} \mathrm{G}_{4},{ }^{3} \mathrm{~F}_{2}, 3$, ${ }^{3} \mathrm{H}_{4},{ }^{3} \mathrm{H}_{5}$, and ${ }^{3} \mathrm{~F}_{4}$. Energy levels above ${ }^{1} \mathrm{G}_{4}$ energy level are not clearly identified because of strong intrinsic bandgap absorption in the host glass. It is also found that the position and shape of five absorption peaks are almost constant with the addition of $\mathrm{BaF}_{2}$.
When $\mathrm{BaF}_{2}$ is added, $\mathrm{F}^{-}$ions crack $\mathrm{O}-\mathrm{H}$ bond in glass network and produce $\mathrm{HF}$ gas so that $\mathrm{OH}^{-}$content is reduced. $\mathrm{OH}^{-}$content is reflected by $\mathrm{OH}^{-}$absorption coefficient $\left(\alpha_{\mathrm{OH}}\right)$ (Wang et al., 2013).

$$
\alpha_{O H}=\frac{\ln \left(T_{0} / T\right)}{l}
$$

where $l$ represents the thickness of glass samples, $\mathrm{T}_{0}$ and $\mathrm{T}$ are the incident and transmitted intensity, respectively. According to FTIR spectra, $\mathrm{OH}^{-}$absorption coefficient of TGB glasses is determined and presented in Figure 3. There are two absorption bands centered at 3.1 and $4.4 \mu \mathrm{m}$, corresponding to stretching mode of free Te-OH groups and/or stretching mode of molecular water and stretching mode of strong hydrogen-bonded Te$\mathrm{OH}$ groups, respectively (Wang et al., 2019). $\alpha_{\mathrm{OH}}$ at $3.1 \mu \mathrm{m}$ is obviously higher than the value at $4.4 \mu \mathrm{m}$. Moreover, $\alpha_{\mathrm{OH}}$ monotonically decreases from 3.4 to $2.2 \mathrm{~cm}^{-1}$ with increasing $\mathrm{BaF}_{2}$ content from 0 to $9 \mathrm{~mol} \%$ in step of $3 \mathrm{~mol} \%$, which is beneficial to improve $1.8 \mu \mathrm{m}$ emission properties of $\mathrm{Tm}^{3+}$ ions.

Figure 4 compares the fluorescence spectra and decay curves of $\mathrm{Tm}^{3+}:{ }^{3} \mathrm{~F}_{4} \rightarrow{ }^{3} \mathrm{H}_{6}$ transition in TGB glasses with different $\mathrm{BaF}_{2}$ amounts pumped by $808 \mathrm{~nm} \mathrm{LD}$. From Figure 4A, it is clear that the spectra are characterized by two emission peaks located at 1,488 and $1,808 \mathrm{~nm}$, corresponding to ${ }^{3} \mathrm{H}_{4} \rightarrow{ }^{3} \mathrm{~F}_{4}$ and ${ }^{3} \mathrm{~F}_{4} \rightarrow{ }^{3} \mathrm{H}_{6}$ transitions, respectively. Emission intensity at $1,488 \mathrm{~nm}$ is obviously weaker than that at $1,808 \mathrm{~nm}$, which is attributed to effective cross relaxation process $\left({ }^{3} \mathrm{H}_{4}+{ }^{3} \mathrm{H}_{6} \rightarrow\right.$ $\left.2^{3} \mathrm{~F}_{4}\right)$. Moreover, emission intensity at $1,488 \mathrm{~nm}$ remains almost unchanged and that near $1.8 \mu \mathrm{m}$ gradually increases with the increment of $\mathrm{BaF}_{2}$ concentration. The peak value near $1.8 \mu \mathrm{m}$ in TGB glasses with $9 \mathrm{~mol} \% \mathrm{BaF}_{2}$ is 1.6 times as high as that without $\mathrm{BaF}_{2}$ because the reduction of $\mathrm{OH}^{-}$content weakens the interaction between $\mathrm{Tm}^{3+}$ and $\mathrm{OH}^{-}$and thus enhances radiative transition probability of ${ }^{3} \mathrm{~F}_{4} \rightarrow{ }^{3} \mathrm{H}_{6}$ transition. Figure $4 \mathrm{~B}$ describes fluorescence decay curves of $\mathrm{Tm}^{3+}:^{3} \mathrm{~F}_{4}$ energy level monitored at $1,808 \mathrm{~nm}$ in TGB glasses with different proportions of $\mathrm{BaF}_{2}$. It is clearly noted that the lifetime of ${ }^{3} \mathrm{~F}_{4}$ energy level gradually prolongs from 337.4 to $577.8 \mu$ s when $\mathrm{BaF}_{2}$ content increases from 0 to $9 \mathrm{~mol} . \%$ in step of $3 \mathrm{~mol} . \%$. The lifetime in TGB glass with $9 \mathrm{~mol} . \% \mathrm{BaF}_{2}$ is 1.7 times as long as the value without $\mathrm{BaF}_{2}$. These results mean that the addition of $\mathrm{BaF}_{2}$ can greatly improve $1.8 \mu \mathrm{m}$ emission properties.

In general, the total decay rate $(\mathrm{W})$ of $\mathrm{Tm}^{3+}:{ }^{3} \mathrm{~F}_{4}$ energy level is defined as the reciprocal of the measured decay lifetime $\left(\tau_{\mathrm{m}}\right)$ and is described by the following equations (Zhou et al., 2010).

$$
\begin{array}{r}
W=1 / \tau_{\mathrm{m}}=A_{\mathrm{r}}+W_{O H}+W_{M P}+W_{E T} \\
W_{O H}=k_{O H-T m} N_{T m} \alpha_{O H}
\end{array}
$$

where $A_{r}$ represents the radiative decay rate, $\mathrm{W}_{\mathrm{OH}}$ is the energy transfer rate between $\mathrm{Tm}^{3+}$ and $\mathrm{OH}^{-}, \mathrm{W}_{\mathrm{mp}}$ is the multiphonon decay rate, $\mathrm{W}_{\mathrm{ET}}$ is the energy transfer rate between $\mathrm{Tm}^{3+}$ ions, $\mathrm{N}_{\mathrm{Tm}}$ is the total concentration of $\mathrm{Tm}^{3+}$ ions and $\alpha_{\mathrm{OH}}$ is $\mathrm{OH}^{-}$ absorption coefficient. $\mathrm{k}_{\mathrm{OH}-\mathrm{Tm}}$ is defined as the strength of interaction between $\mathrm{Tm}^{3+}$ and $\mathrm{OH}^{-}$and doesn't rely on the 

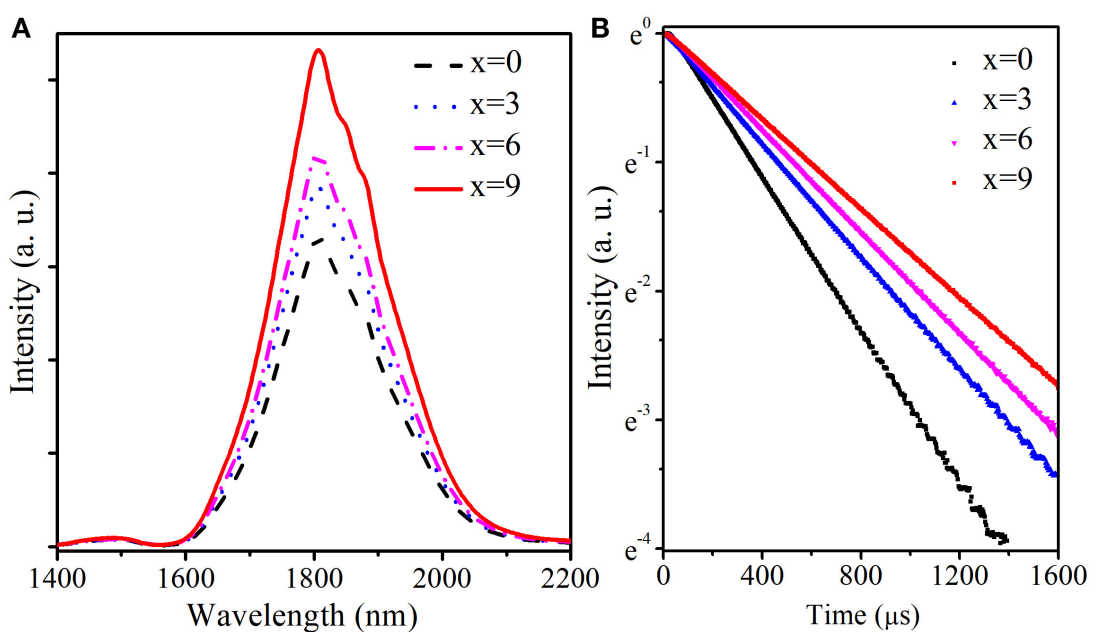

FIGURE 4 | (A) Fluorescence spectra and (B) decay curves of $\mathrm{Tm}^{3+}:{ }^{3} \mathrm{~F}_{4}$ energy level in TGB glasses with different proportions of BaF 2 pumped by $808 \mathrm{~nm}$ LD.

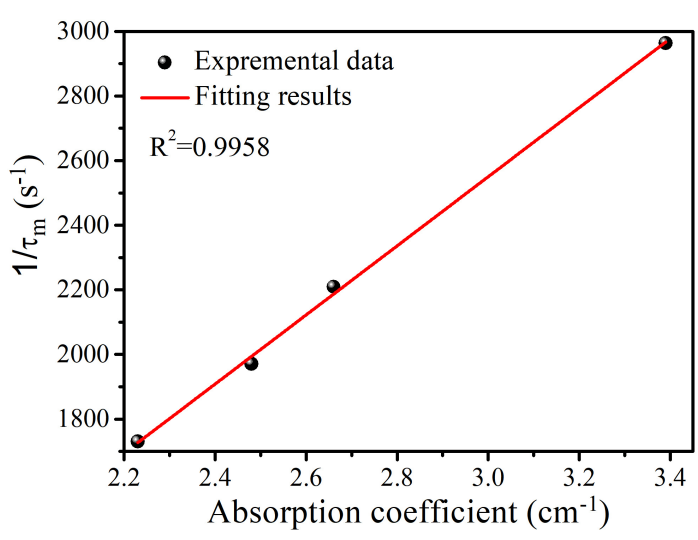

FIGURE 5 | The dependence of the total decay rate on $\alpha_{\mathrm{OH}}$ along with the red fitting curve.

concentrations of $\mathrm{Tm}^{3+}$ and $\mathrm{OH}^{-}$. Figure 5 represents a good linear relationship between the total decay rate and $\alpha_{\mathrm{OH}}$. From this fit, $\mathrm{k}_{\mathrm{OH}-\mathrm{Tm}}$ is determined and equals to $2.82 \times 10^{-18} \mathrm{~cm}^{4} / \mathrm{s}$, which is larger than $\mathrm{k}_{\mathrm{OH}-\mathrm{Er}}\left(1.9 \times 10^{-19} \mathrm{~cm}^{4} / \mathrm{s}\right)$ (Zhou et al., $2010)$ and lower than $\mathrm{k}_{\mathrm{OH}-\mathrm{Tm}}\left(7.89 \times 10^{-18} \mathrm{~cm}^{4} / \mathrm{s}\right)$ in germanate glasses (Wang et al., 2014).

Based on above-mentioned results, Figure 6 shows energy transfer mechanism. Under excitation at $808 \mathrm{~nm} \mathrm{LD} \mathrm{Tm}^{3+}$ ions are motivated to ${ }^{3} \mathrm{H}_{4}$ state from the ${ }^{3} \mathrm{H}_{6}$ ground state. Then, a few $\mathrm{Tm}^{3+}$ ions return radiatively to ${ }^{3} \mathrm{~F}_{4}$ state with $1,488 \mathrm{~nm}$ photon. However, the majority of ions relax nonradiatively to ${ }^{3} \mathrm{~F}_{4}$ state via muliphonon relaxation process and efficient cross relaxation process (CR) between two adjacent $\mathrm{Tm}^{3+}$ ions $\left({ }^{3} \mathrm{H}_{4}+{ }^{3} \mathrm{H}_{6} \rightarrow\right.$ $\left.2^{3} \mathrm{~F}_{4}\right)$. Finally, $\mathrm{Tm}^{3+}$ ions in the excited ${ }^{3} \mathrm{~F}_{4}$ state return to the ${ }^{3} \mathrm{H}_{6}$ ground state, emitting fluorescence at $1.8 \mu \mathrm{m}$. Significantly, the residual $\mathrm{OH}^{-}$in TGB glasses can impair $1.8 \mu \mathrm{m}$ emission via two $\mathrm{OH}^{-}$ions, indicating that it is essential to decrease the hydroxyl content for improving $1.8 \mu \mathrm{m}$ emission.

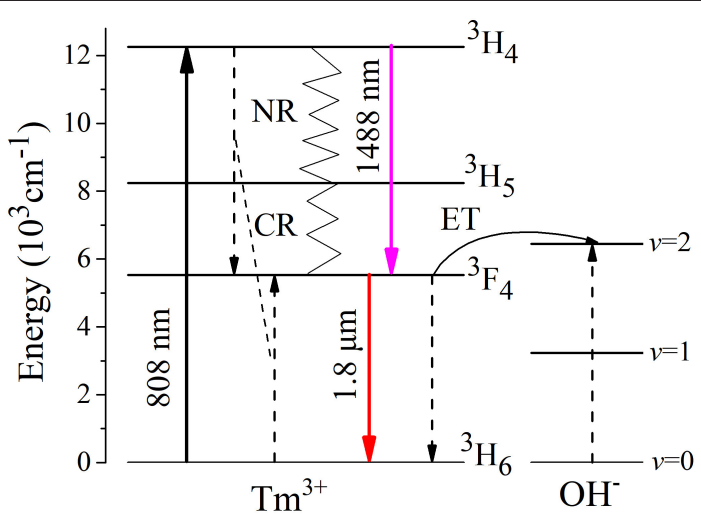

FIGURE 6 | The energy level diagram and energy transfer mechanism of $\mathrm{Tm}^{3+}$ ions.

Both absorption and emission cross sections of $\mathrm{Tm}^{3+}$ ions are very crucial parameters to evaluate the potential of TGB glasses as $2 \mu \mathrm{m}$ laser material. Based on the Beer-Lambert equation and Fuchtbauer-Ladenburg equation (Chen et al., 2007), absorption and emission cross sections of $\mathrm{Tm}^{3+}:{ }^{3} \mathrm{H}_{6} \leftrightarrow{ }^{3} \mathrm{~F}_{4}$ transition in TGB glass with $9 \mathrm{~mol} \% \mathrm{BaF}_{2}$ are calculated and presented in Figure 7A. The maximum absorption cross section of $\mathrm{Tm}^{3+}$ reaches $5.3 \times 10^{-21} \mathrm{~cm}^{2}$ at $1,706 \mathrm{~nm}$, which is higher than that of silicate glass $\left(1.5 \times 10^{-21} \mathrm{~cm}^{2}\right)$ (Li et al., 2012), fluorophosphate glass $\left(3.0 \times 10^{-21} \mathrm{~cm}^{2}\right)$ (Li et al., 2015), tellurium germanate glass $\left(3.2 \times 10^{-21} \mathrm{~cm}^{2}\right)$ (Gao et al., 2015) and germanate glass $\left(4.1 \times 10^{-21} \mathrm{~cm}^{2}\right)$ (Yu et al., 2009). Moreover, corresponding maximum emission cross section is $8.8 \times 10^{-21} \mathrm{~cm}^{2}$ at $1,814 \mathrm{~nm}$, which is higher than that of silicate glass $\left(3.6 \times 10^{-21} \mathrm{~cm}^{2}\right)(\mathrm{Li}$ et al., 2012), fluorophosphate glass $\left(5.5 \times 10^{-21} \mathrm{~cm}^{2}\right)$ (Li et al., $2015)$, tellurium germanate glass $\left(6.8 \times 10^{-21} \mathrm{~cm}^{2}\right)$ (Gao et al., 2015), germanate glass $\left(5.5 \times 10^{-21} \mathrm{~cm}^{2}\right)(Y u$ et al., 2009) and zinc tellurite glass $\left(7.3 \times 10^{-21} \mathrm{~cm}^{2}\right)$ (Yuan and Xiao, 2018). The 

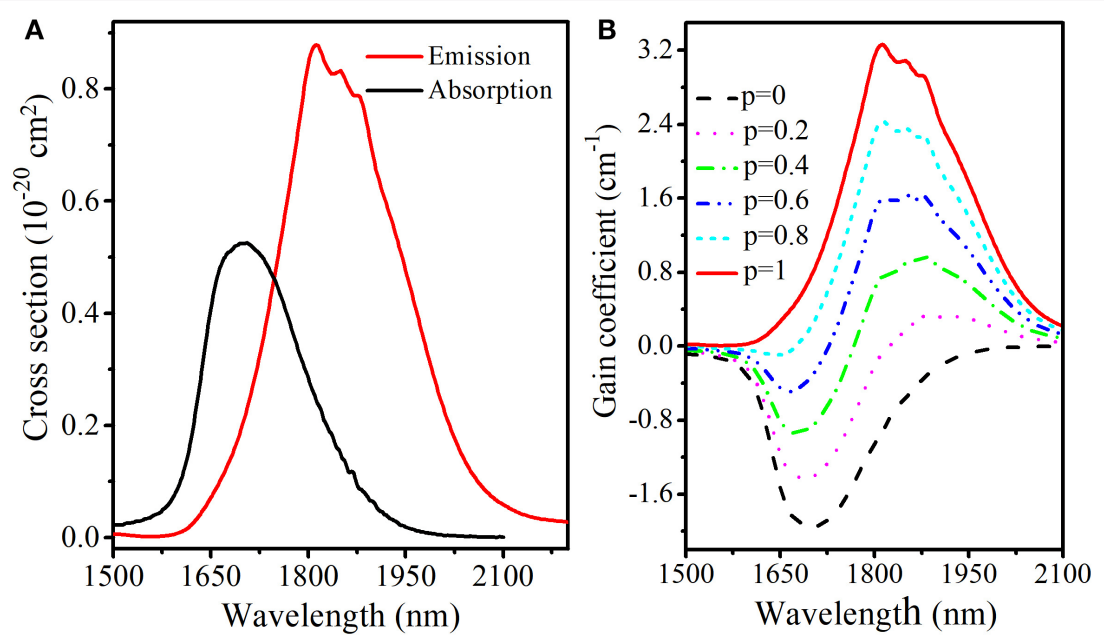

FIGURE 7 | (A) Absorption, emission cross section and (B) calculated gain coefficient of TGB glass with 9 mol.\% $\mathrm{BaF}_{2}$.

high emission cross section of TGB glass with 9 mol. $\% \mathrm{BaF}_{2}$ is helpful to provide high laser gain.

Once absorption and emission cross sections are determined and it is supposed that $\mathrm{Tm}^{3+}$ ions are only in either the ${ }^{3} \mathrm{H}_{6}$ or ${ }^{3} \mathrm{~F}_{4}$ state, the gain coefficient $G(\lambda)$ of $\mathrm{Tm}^{3+}$ near $1.8 \mu \mathrm{m}$ can be obtained by the following equation (Zou and Toratani, 1996).

$$
G(\lambda)=N\left[p \sigma_{e}-(1-p) \sigma_{a}\right]
$$

where $N$ represents the total concentration of $\mathrm{Tm}^{3+}$ ions and $p$ is the inversion factor given by the ratio between the population of lasing upper level $\left({ }^{3} \mathrm{~F}_{4}\right)$ and the total concentration that ranges from 0 to 1 . Figure $7 \mathbf{B}$ shows gain coefficient spectrum of TGB glass with $9 \mathrm{~mol} \% \mathrm{BaF}_{2}$. It is found that the gain peak shifts to shorter wavelength with increasing $p$, which is a typical feature of the quasi-three-level system. Moreover, gain coefficient starts to be greater than zero in the wavelength range from 1,824 to $2,100 \mathrm{~nm}$ when $p \geq 0.2$ and the maximum value is $3.3 \mathrm{~cm}^{-1}$ at $1,814 \mathrm{~nm}$, which is larger than that of silicate glass $\left(2.57 \mathrm{~cm}^{-1}\right)$ (Tang et al., 2016), germanate glass $\left(2.11 \mathrm{~cm}^{-1}\right)$ (Slimen et al., 2019) and tellurite glass $\left(0.91 \mathrm{~cm}^{-1}\right)$ (Tian et al., 2019). This means that TGB glass with 9 mol. $\% \mathrm{BaF}_{2}$ is a promising host material for efficient $2.0 \mu \mathrm{m}$ fiber laser development.

\section{CONCLUSIONS}

In summary, the effects of $\mathrm{BaF}_{2}$ contents on density, refractive index, Raman spectra, $\mathrm{OH}^{-}$absorption coefficient and $1.8 \mu \mathrm{m}$ spectroscopic properties of $\mathrm{Tm}^{3+}$ doped gallium tellurite glasses are studied in detail. When $\mathrm{BaF}_{2}$ content increases from 0 to 9 mol.\% in step of $3 \mathrm{~mol} . \%$, refractive index and density gradually reduce. Meanwhile, $\alpha_{\mathrm{OH}}$ monotonically decreases from 3.4 to $2.2 \mathrm{~cm}^{-1}$, which makes emission peak value near $1.8 \mu \mathrm{m}$ in TGB glass with 9 mol.\% $\mathrm{BaF}_{2}$ being 1.6 times as large as that without $\mathrm{BaF}_{2}$ while the lifetime becomes 1.7 times as long as the value without $\mathrm{BaF}_{2}$. The maximum emission cross section at around $1.8 \mu \mathrm{m}$ of $\mathrm{TGB}$ glass with $9 \mathrm{~mol} \% \mathrm{BaF}_{2}$ reaches $8.8 \times 10^{-21} \mathrm{~cm}^{2}$. In addition, positive gain coefficient in the wavelength range from 1,824 to $2,100 \mathrm{~nm}$ is achieved when $p \geq 0.2$ and the maximum gain coefficient is $3.3 \mathrm{~cm}^{-1}$ at $1,814 \mathrm{~nm}$. As a result, TGB glass with $9 \mathrm{~mol} \% \mathrm{BaF}_{2}$ appears to be a highly promising host material for efficient $2.0 \mu \mathrm{m}$ fiber laser development.

\section{DATA AVAILABILITY STATEMENT}

The raw data supporting the conclusions of this article will be made available by the authors, without undue reservation.

\section{AUTHOR CONTRIBUTIONS}

JY, PX, and WW conceived the idea. JY and PX wrote the paper. TD, YY, DO, JC, and SY advised the paper. All authors contributed to the article and approved the submitted version.

\section{FUNDING}

The authors gratefully acknowledge the financial support from the National Natural Science Foundation of China (Grant Nos. 51902053 and 61804029), Natural Science Foundation of Guangdong province (Grant Nos. 2019A1515011988 and 2018A030310353), Guangdong Basic and Applied Basic Research Foundation (Grant No. 2019A1515110002), the Foundation for Distinguished Young Talents in Higher Education of Guangdong (Grant No. 2019KQNCX172), the Project of Foshan Education Bureau (Grant No. 2019XJZZ02), GuangdongHong Kong-Macao Intelligent Micro-Nano Optoelectronic Technology Joint Laboratory (Grant No. 2020B1212030010), and the Open Fund of the State Key Laboratory of Luminescent Materials and Devices (South China University of Technology, Grant No. 2020-skllmd-13). 


\section{REFERENCES}

Agger, S., Povlsen, J. H., and Varming, P. (2004). Single-frequency thuliumdoped distributed-feedback fiber laser. Opt. Lett. 29, 1503-1505. doi: 10.1364/OL.29.001503

Chen, G. X., Zhang, Q. Y., Yang, G. F., and Jiang, Z. H. (2007). Mid-infrared emission characteristic and energy transfer of $\mathrm{Ho}^{3+}$-doped tellurite glass sensitized by $\mathrm{Tm}^{3+}$. J. Fluoresc. 17, 301-307. doi: 10.1007/s10895-007-0173-5

Chen, Y. J., Lin, Y. F., Gong, X. H., Zhu, H. M., Luo, Z. D., and Huang, Y. D. (2010). 805-nm diode-pumped continuous-wave 2- $\mu \mathrm{m}$ laser performance of $\mathrm{Tm}^{3+}: \mathrm{BaGd}_{2}\left(\mathrm{MoO}_{4}\right)_{4}$ cleavage plate. Appl. Phys. B. 98, 55-60. doi: $10.1007 / \mathrm{s} 00340-009-3704-8$

Gao, S., Kuan, P. W., Liu, X. Q., Chen, D. P., Liao, M. S., and $\mathrm{Hu}$, L. L. (2015). $\sim 2-\mu \mathrm{m}$ single-mode laser output in $\mathrm{Tm}^{3+}$-doped tellurium germanate double-cladding fiber. IEEE Photon. Technol. Lett. 27, 1702-1704. doi: 10.1109/LPT.2015.2438077

Geng, J. H., and Jiang, S. B. (2014). Fiber lasers:the $2 \mu \mathrm{m}$ market heats up. Opt. Photonics News. 25, 35-41. doi: 10.1364/OPN.25.7.000034

Geng, J. H., Wang, Q., and Jiang, S. B. (2011). $2 \mu \mathrm{m}$ fiber laser sources and their applications. Proc. SPIE. 8164:816409. doi: 10.1117/12.896259

He, X., Xu, S. H., Li, C., Yang, C. S., Yang, Q., Mo, S. P., et al. (2013). $1.95 \mu \mathrm{m} \mathrm{kHz}$-linewidth single-frequency fiber laser using self-developed heavily $\mathrm{Tm}^{3+}$-doped germanate glass fiber. Opt. Exp. 21, 20800-20805. doi: 10.1364/OE.21.020800

Jose, R., Arai, Y., and Ohishi, Y. (2007). Raman scattering characteristics of the TBSN-based tellurite glass system as a new Raman gain medium. J. Opt. Soc. Am. B. 24,1517-1526. doi: 10.1364/JOSAB.24.001517

Li, L. X.; Wang, W. C., Zhang, C. F., Liu, J. L., Zhang, Q. Y., and Jiang, Z. H. (2019). Exploration of the new tellurite glass system for efficient $2 \mu \mathrm{m}$ luminescence. $J$. Non Cryst. Solids 508, 15-20. doi: 10.1016/j.jnoncrysol.2018.12.018

Li, M., Bai, G. X., Guo, Y. Y., Hu, L. L., and Zhang, J. J. (2012). Investigation on $\mathrm{Tm}^{3+}$-doped silicate glass for $1.8 \mu \mathrm{m}$ emission. J. Lumin. 132, 1830-1835. doi: 10.1016/j.jlumin.2012.02.022

Li, R. B., Tian, C., Tian, Y., Tao, W., Li, B. P., Jing, X. F., et al. (2015). Mid-infrared emission properties and energy transfer evaluation in $\mathrm{Tm}^{3+}$ doped fluorophosphate glasses. J. Lumin. 162, 58-62. doi: 10.1016/j.jlumin.2015.02.016

Mao, L. Y., Liu, J. L., Li, L. X., and Wang, W. C. (2020). $\mathrm{TeO}_{2}-\mathrm{Ga}_{2} \mathrm{O}_{3}-\mathrm{ZnO}$ ternary tellurite glass doped with $\mathrm{Tm}^{3+}$ and $\mathrm{Ho}^{3+}$ for $2 \mu \mathrm{m}$ fiber lasers. J. Non Cryst. Solids 531:119855. doi: 10.1016/j.jnoncrysol.2019.119855

Murugan, G. S., and Ohishi, Y. (2004). Raman spectroscopic studies of $\mathrm{TeO}_{2}$ $\mathrm{BaO}-\mathrm{SrO}-\mathrm{Nb}_{2} \mathrm{O}_{5}$ glasses: structure-property correlations. J. Appl. Phys. 96, 2437-2442. doi: 10.1063/1.1772890

Richards, B., Jha, A., Tsang, Y., Binks, D., Lousteau, J., Fusari, F., et al. (2010). Tellurite glass lasers operating close to $2 \mu \mathrm{m}$. Laser Phys. Lett. 7, 177-193. doi: 10.1002/lapl.200910131

Slimen, F. B., Chen, S. X., Lousteau, J., Jung, Y. M., White, N., Alam, S., et al. (2019). Highly efficient $\mathrm{Tm}^{3+}$ doped germanate large mode area single mode fiber laser. Opt. Mater. Exp. 9, 4115-4125. doi: 10.1364/OME.9.004115

Tang, G. W., Zhu, T. T., Liu, W. W., Qiao, T., Sun, M., Chen, D. D., et al. (2016). $\mathrm{Tm}^{3+}$ doped lead silicate glass single mode fibers for $2.0 \mu \mathrm{m}$ laser applications. Opt. Mater. Exp. 6, 2147-2157. doi: 10.1364/OME.6.002147
Terra, I. A.,A; Camargo, A. S. S., Nunes, L. A. O., Carvalho, R. A., and Li, M. S. (2006). Evaluation of the $\mathrm{OH}^{-}$influence on visible and near-infrared quantum efficiencies of $\mathrm{Tm}^{3+}$ and $\mathrm{Yb}^{3+}$ codoped sodium aluminophoshate glasses. J. Appl. Phys. 100:123103. doi: 10.1063/1.2400510

Tian, Y., Li, B. P., Wang, J. R., Liu, Q. H., Chen, Y. L., Zhang, J. J., et al. (2019). The mid-infrared emission properties and energy transfer of $\mathrm{Tm}^{3+} / \mathrm{Er}^{3+}$ codoped tellurite glass pumped by $808 / 980 \mathrm{~nm}$ laser diodes. J. Lumin. 214:116586. doi: 10.1016/j.jlumin.2019.116586

Wang, R. S., Meng, X. W., Yin, F. X., Feng, Y., Qin, G. S., and Qin, W. P. (2013). Heavily erbium-doped low-hydroxyl fluorotellurite glasses for $2.7 \mu \mathrm{m}$ laser applications. Opt. Mater. Exp. 3, 1127-1136. doi: 10.1364/OME.3.0 01127

Wang, W. C., Yuan, J., Liu, X. Y., Chen, D. D., Zhang, Q. Y., and Jiang, Z. H. (2014). An efficient $1.8 \mu \mathrm{m}$ emission in $\mathrm{Tm}^{3+}$ and $\mathrm{Yb}^{3+} / \mathrm{Tm}^{3+}$ doped fluoride modified germanate glasses for a diode-pump mid-infrared laser. J. Non Cryst. Solids 404, 19-25. doi: 10.1016/j.jnoncrysol.2014. 07.026

Wang, W. C., Zhou, B., Xu, S. H., Yang, Z. M., and Zhang, Q. Y. (2019). Recent advances in soft optical glass fiber and fiber lasers. Progr. Mater. Sci. 101, 90-171. doi: 10.1016/j.pmatsci.2018.11.003

Yang, X. L., Wang, W. C., and Zhang, Q. Y. (2017). $\mathrm{BaF}_{2}$ modified $\mathrm{Cr}^{3+} / \mathrm{Ho}^{3+}$ co-doped germanate glass for efficient $2.0 \mu \mathrm{m}$ fiber lasers. J. Non Cryst. Solids 482, 147-153. doi: 10.1016/j.jnoncrysol.2017.12.031

Yu, S. L., Yang, Z. M., and Xu, S. H. (2009). Judd-Ofelt and laser parameterization of $\mathrm{Tm}^{3+}$-doped barium gallo-germanate glass fabricated with efficient dehydration methods. Opt. Mater. 31, 1723-1728. doi: 10.1016/j.optmat.2009.05.002

Yuan, J., Wang, W. C., Chen, D. D., Peng, M. Y., Zhang, Q. Y., and Jiang, Z. H. (2014). Enhanced $1.8 \mu \mathrm{m}$ emission in $\mathrm{Yb}^{3+} / \mathrm{Tm}^{3+}$ codoped tungsten tellurite glasses for a diode-pump $2.0 \mu \mathrm{m}$ laser. J. Non Cryst. Solids 402, 223-230. doi: 10.1016/j.jnoncrysol.2014.06.008

Yuan, J., and Xiao, P. (2018). Compositional effects of $\mathrm{Na}_{2} \mathrm{O}, \mathrm{GeO}_{2}$, and $\mathrm{Bi}_{2} \mathrm{O}_{3}$ on $1.8 \mu \mathrm{m}$ spectroscopic properties of $\mathrm{Tm}^{3+}$ doped zinc tellurite glasses. J. Lumin. 196, 281-284. doi: 10.1016/j.jlumin.2017.12.054

Zhou, Y. X., Gai, N., Chen, F., and Yang, G. B. (2010). Effect of hydroxyl groups in erbium-doped tellurite- and bismuth-based glasses. Opt. Fiber Technol. 16, 318-322. doi: 10.1016/j.yofte.2010.08.002

Zou, X. L., and Toratani, H. (1996). Spectroscopic properties and energy transfers in $\mathrm{Tm}^{3+}$ singly- and $\mathrm{Tm}^{3+} / \mathrm{Ho}^{3+}$ doubly-doped glasses. J. Non Cryst. Solids 195, 113-124. doi: 10.1016/0022-3093(95)00522-6

Conflict of Interest: The authors declare that the research was conducted in the absence of any commercial or financial relationships that could be construed as a potential conflict of interest.

Copyright (c) 2021 Yuan, Wang, Ye, Deng, Ou, Cheng, Yuan and Xiao. This is an open-access article distributed under the terms of the Creative Commons Attribution License (CC BY). The use, distribution or reproduction in other forums is permitted, provided the original author(s) and the copyright owner(s) are credited and that the original publication in this journal is cited, in accordance with accepted academic practice. No use, distribution or reproduction is permitted which does not comply with these terms. 